\title{
Psychometric properties and Factor structure of the BRCS in an elderly Spanish sample
}

\author{
Carmen Moret-Tatay ${ }^{1}$, Juan José Fernández Muñoz ${ }^{2}$, Cristina Civera Mollá ${ }^{3}$, \\ Esperanza Navarro-Pardo ${ }^{4 *}$ y Carlos $\mathrm{M}^{\mathrm{a}}$ Alcover de la $\mathrm{Hera}^{2}$
}

\author{
1 Departamento de Neuropsicobiología, Metodologia y Psicología Social. Facultad de Psicologia, Magisterio y Ciencias de la Educación. Universidad Católica de Valencia "San Vicente \\ Mártir", Valencia (Spain). \\ 2 Departamento de Medicina y Cirugía, Psicología, Medicina Preventiva y Salud Pública e Inmunología y Microbiología Médica. Facultad de Ciencias de la Salud. Universidad Rey \\ Juan Carlos, Madrid (Spain). \\ 3 Departamento de Psicología Básica. Facultad de Psicología. Universitat de València, Valencia (Spain). \\ 4 Departamento de Psicología Evolutiva y de la Educación. Facultad de Psicología. Universitat de València. Valencia (Spain).
}

\begin{abstract}
Título: Propiedades psicométricas y estructura factorial del BRCS en una muestra de personas mayores españolas.

Resumen: La resiliencia exitosa es una variable a menudo relacionada con un proceso óptimo envejecimiento. Sin embargo, la literatura es más bien limitada en relación a instrumentos de evaluación para los adultos mayores en el idioma español. El objetivo de este trabajo es validar la escala breve de resiliencia BRCS (Sinclair \& Wallston, 2004), una escala de cuatro punto Likert, en personas mayores españolas. Para ello, la escala se administró a una muestra de 991 adultos mayores españoles, y fue analizada en términos de análisis factorial exploratorio y confirmatorio, consistencia interna y validez de criterio. La escala demostró buenas propiedades psicométricas. Además, los índices de homogeneidad fueron más altos que los mostrados en la literatura recientemente, reforzando la estructura dimensional de la escala. Estos resultados han mostrado una mayor fiabilidad frente a las anteriores versiones españolas anteriores. Por lo tanto, el BRCS es un instrumento de evaluación que podría ser muy útil en la evaluación de la resiliencia de los adultos mayores de habla española.

Palabras clave: Escala Breve de Resiliencia; validación; adultos mavores.
\end{abstract}

Abstract: Successful resilience is a variable often related to an optimal aging process. However, literature is rather limited when dealing with assessment instruments for the elderly in the Spanish language. The objective of this work is to validate the Brief Resilient Coping Scale (Sinclair \& Wallston, 2004), a four item likert scale, in the Spanish elderly. For this propose, the scale was administrated to a sample of 991 elderly Spanish participants, and the data set analysed in terms of exploratory and confirmatory factor analysis, internal consistency and criterion validity. The scale demonstrated good psychometric properties. Furthermore, the homogeneity indices were higher than the recently literature, reinforcing the dimensional structure of the scale. These results have shown higher reliability from previous Spanish versions. Therefore, the Brief Resilient Coping Scale is a valuable assessment instrument that could be very useful in the assessing of resilience in the Spanish-speaking elderly.

Key words: Brief Resilient Coping Scale; validation; elderly.

\section{Introduction}

Resilience is a concept taken from physics. It is defined as the characteristic of matter to resist or recover its original shape after experiencing high pressures (McAslan, 2009). This term has also been applied to other fields, such as Psychology. In this latter field, the concept of resilience has been understood as how humans react to stressful events or adversities (i.e. health issues). Furthermore, it also can be understood as a dynamic concept that may vary during the different stages of human life, for example, during the aging process. In fact, some research has come to use it as an indicator of successful aging (Wagnild, 2003).

More recently, several studies have tried to link resilience with variables such as stress (Diehl \& Hay, 2010) or place of residence (Tanaka, \& Johnson, 2010), but certainly one of the variables inherent in human's span is the coping concept (Cabib, Campus, \& Colelli, 2012). This concept could be defined as cognitive and behavioural efforts that a person performs in order to deal with different demands, internal and/or external. This concept is directly linked to the concept of resilience. Hence the utility in the content validation of resilience assessment scales.

Given the theoretical and applied nature of this concept, it is not surprising that many studies have raised this topic

* Dirección para correspondencia [Correspondence address]: Esperanza Navarro-Pardo. Departamento de Psicología Evolutiva y de la Educación. Facultad de Psicología. Universitat de València. Av. Blasco Ibáñez, 21, 46010 - Valencia (Spain). E-mail: esperanza.navarro@uv.es from various areas of psychology in the last decade (Shaikh et al., 2010; Staudinger, Marsiske, \& Baltes, 1995). Actually, research lines involve psychometric studies (Bartone, 1989; Connor \& Davidson, 2003, Tomas et al., 2012; Wallston and Sinclair, 2004) or even neuroimaging techniques (Waugh et al., 2008).

Currently, one of the emerging themes is the role of resilience in the aging process. Humans, like other species, face a large number of normative and non-normative changes however the aging process has many differences between subjects. In fact, authors such as Rowe and Kahn (1987) distinguish three aging process categories: optimal aging, nor$\mathrm{mal}$ and pathological. Some research works (Staudinger, Marsiske, \& Baltes, 1995; Vinaccia, Quiceno, \& Remor, 2012; von Faber et al., 2001) have suggested that variables such as resilience could be related to the development of successful aging.

A high number of scales have been developed for the purpose of measuring resilience, demonstrating optimal psychometric properties, both in its reliability and validity. For example: the Resilience Scale (Wagnild \& Young, 1993); the Dispositional Resilience Scale (Bartone, 1989); or the Brief Resilient Coping Scale (Sinclair and Wallston, 2004). The purpose of this work was to validate this latter scale, the Brief Resilient Coping Scale (Sinclair \& Wallston, 2004). The main benefit being as it is a one-dimensional scale it might enable application in the elderly for native Spanish speakers. Indeed, his first Spanish-language adaptation seems to show good levels of validity and reliability, as shown by Tomas, 
Melendez, Sancho and Mayordomo (2012) in an initial validation of the Brief Resilient Coping Scale (BRCS) with a sample of 133 elderly Spanish. Bear in mind the importance of adapting these instruments to other languages, as the vast majority are developed for English speaking population. Furthermore, one should keep in mind that the Tomas et al. (2012) research work is an initial validation. Caution is advised not to make firm conclusions regarding results with a small sample size.

Given the need to develop instruments like the BCRS, that allow us to measure the variable of interest, in this instance resilience, we consider it essential to carry out a validation of the BCRS for an elderly Spanish population with an optimum sample size. Therefore, the main objective of this study was to analyse the internal consistency and factor structure of the Spanish version BCRS in a sample of retired Spanish people. This will allow us to have an instrument for measuring resilience in the Spanish and gain the possibility to distinguish between different levels of resilience. To date this has been a challenge as tools only exist in the English language. As mentioned earlier, the development of this capacity throughout life, especially in in the elderly, could be related to the development of optimal aging (Staudinger, Marsiske, \& Baltes, 1995). Therefore, such instruments are very useful and valuable to conduct inferences and generalisations.

\section{Method}

\section{Participants}

The sample selected was composed of 991 retirees, from whom $75.9 \%$ were male and $24.2 \%$ were women. The average age was 62.7 years $(S D=5.89)$, with an age range of 50 85. Educational Attainment: $11.9 \%$ had no education; $31.6 \%$ completed basic education; $32.9 \%$ secondary level studies completed and $18.2 \%$ finished third level. Marital Status: $56.7 \%$ were single; $10 \%$ married; $5.2 \%$ widowed and $2.4 \%$ divorced. As for the professional category: $7.6 \%$ were managers; $6.5 \%$ middle management; $14.7 \%$ technicians; $25 \%$ skilled workers; $11 \%$ unskilled workers and 15.2\% administrative employees. Finally, in relation to the professional sector, $32.2 \%$ belonged to the public sector while $43.2 \%$, the private sector.

\section{Instruments}

Among the scales used were the Brief Resilient Coping Scale (BRCS) and the Brief COPE (Carver, 1997), as well as a module on demographic data such as age, gender, marital status, educational attainment, the profession, the industry in which they worked, etc.

Sinclair and Wallston (2004) developed the Brief Resilient Coping Scale (BRCS). This scale resilience assimilates optimism, perseverance, creativity and positive growth in the face of adversity. The authors describe a resilient coping pat- tern as reflecting a model of active problem solving. The BCRS is a measurement tool that has proven resilience with adequate levels of reliability and validity. The original scale consists of 4 items and a single factor or dimension, with an index of internal consistency of $\alpha=.69$ and test-retest reliability of $.71(\mathrm{n}=87, p<.001)$. The goodness of fit indices showed an excellent fit: $X^{2}=2.13, p=.03$, CFI $=.99$, SRMR $=.02$ and RMSEA $=.01$ (Sinclair \& Wallston, 2004). The format is Likert response with 6 anchor points, from 0 (does not describe me at all) to 6 (describes me very well). The maximum score is 20 points, the higher the score the greater resilience. According to the authors of the original scale, low-resistance subjects are those whom obtain scores lower than 13, while those who scored above 17 are considered highly adaptable. This is a self-administered scale, which aims to assess the ability to handle stress in an adaptive manner. Originally developed in English but translated into Spanish for the purposes of this study.

To BRCS original language is English, a translation into Spanish was carried out following Harkness \& SchouaGlusberg (1998) procedure by the first of four people selected for the translation process. The second person took this Spanish translation and translated it back into English without knowledge of the original English version. The fourth person compared the two preliminary English translations and determined, statement by statement, if they were equivalent in meaning. For statements where there were discrepancies a panel was formed with the first, second and fourth persons. Modifications to the statements were agreed and amended to the Spanish version generating the final version of the questionnaire.

In contrast, the Brief COPE (Carver, 1997) is a multidimensional scale for assessing coping styles that evaluates 14 different coping strategies: active coping; planning; coping/positive reframing; acceptance; humour; religion; emotional support; instrumental support; self-distraction; denial; behavioural disengagement; substance use or drug refusal behaviour and self-blame. This was employed to examine content validity. This is a 28 -item instrument with responses from 1 (not at all) to 4 (yes, a lot) which aims to assess how people respond when faced with difficult or stressful events. The strategies included in this work are, first, those that involve active coping problems (seeking emotional social support, seeking instrumental social support, planning and active coping, venting, positive reinterpretation, humour, acceptance, religion and self-blame) and, secondly, avoidant coping strategies (self-distraction, denial, alcohol and drug consumption and behavioural disconnection). The COPE shows adequate psychometric characteristics. Internal reliability of all scales is greater than 50 (Carver, 1997). No psychometric data is currently available for Short COPE Spanish population. However, the original version of 60 items in Spanish population (Carver, Scheier \& Weintraub, 1989) has good internal consistency (over 0.6) for all scales except two (distracting activities and evasion). Furthermore, test-retest 
reliability for seven weeks has values ranging between 0.34 and 0.96 (Crespo \& Cruzado, 1997).

The COPE translation to Spanish was similar to the methodology employed in BRCS.

\section{Procedure}

Sampling procedure was incidental. Seniors were enrolled in university programs for older people from different Spanish universities during 2011-2012. Prior to the final preparation of the questionnaire, a pilot selection of 60 people was carried out, reviewing the responses, testing coding and meanings of the translated items of the original instrument. The questionnaire was self-administered under the supervision of trained psychologists, during one of the classes, with permission from both the University and the teacher responsible for the class. Participants were volunteers and completed the necessary informed consent documentation.

\section{Analysis}

To perform the analysis we used SPSS 18.0 for exploratory factor analysis (EFA), and Amos 18.0 module for confirmatory factor analysis (CFA). Assumptions were checked to ensure the application of factor analysis, high sample size, multivariate normality, linearity and correlation between variables (Comrey, 1973; Tabachnick \& Fidell, 1989). To carry out the AFE a Varimax rotation method was applied, accepting those factors with an eigenvalue greater than 1 (Harman, 1976; Kaiser, 1958). We checked for internal consistency of the scale through Cronbach Alpha; items of homogeneity; KMO index and the Bartlett test of sphericity (Kaiser, 1974).
After removing the factorial solution proceeded to the completion of confirmatory factor analysis (CFA), accompanied by the goodness of fit indices. Confirmation of the adequacy of the model have been used within the absolute fit indices; the chi-square statistic $X^{2}$ (Jöreskog \& Sörbom, 1979; Saris \& Stronkhorst, 1984); the goodness of fit index (GFI) whose value reference is at 90 to consider an acceptable model (Hu \& Bentler, 1990), the square root of the mean square residues (RMSR) based directly on the residues, whether they are close to 0 , the value of RMSR is 0 , therefore, the lower the value, the better the fit, the reference value is .08 (Jöreskog \& Sörbom, 1979), within the incremental fit indices, the comparative fit index (CFI), normed fit index (NFI), also called delta 1 and the incremental fit index (IFI), in all three cases the range of values between 0 and 1 and the reference value is 90 (Bentler, 1990; Bollen, 1989; Bentler \& $\mathrm{Hu}, 1990)$, and finally, within parsimony adjustment indices, the error of the root mean square approximation (RMSEA) of the RMSR Similarly, the more smaller its value, the better the fit, the reference value being .05 (Steiger \& Lind, 1980).

\section{Results}

\section{Internal consistency}

Cronbach's alpha of the BRCS scale (Sinclair and Wallston, 2004) was $\alpha=.86$, and the percentage of total variance explained of $70.39 \%$. Table 1 presents the descriptive analysis, homogeneity items, Cronbach's alpha and correlations between items. In this sense, items of homogeneity were significantly elevated with a minimum value of 67 (item 1) and a maximum value of 77 (item 3). Moreover, bivariate correlations between the items ranged from a minimum of $r$ $=0.52$ and a maximum of $r=0.73$ (item 4).

Table 1. Means, standard deviations, item homogeneity, $\alpha$ if item deleted and inter-item correlation for the four items of the Brief Resilient Coping Scale (BRCS)

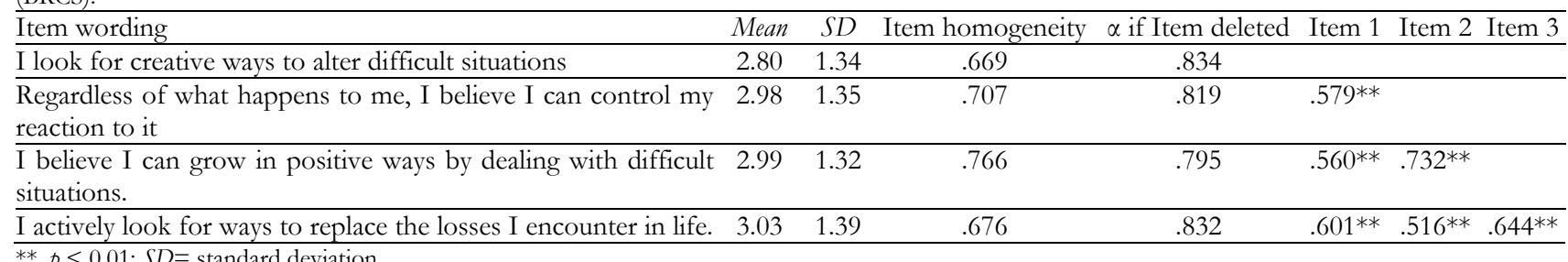

\section{Exploratory and Confirmatory Factor Analysis}

In relation to the validity of Exploratory Factor Analysis (EFA), the Bartlett's test of sphericity was $p<.001$ with a value of chi-square $1763.23(d f=6)$ and the sample index value of Kaiser-Meyer-Olkin (KMO) was 0.76. The AFC has confirmed the existence of a single factor. The factor loadings from the exploratory factor solution were: "I look for creative ways to alter Difficult situations" (item 1) $=.73$, "Regardless of what happens to me, I believe I can check my reaction to it" (item 2 ) $=.83$, "I believe I can grow in posi- tive ways by dealing with Difficult situations" (item 3 ) $=.88$, and "I Actively look for ways to replace the Losses I encounter in life" (item 4) =. 76. The model presented an optimal fit, except the RMSEA, which exceeds the recommended value $=.08$. The goodness of fit indices global scale was: $X^{2}=107.02 \mathrm{p}<.001(d f=2)$, GFI $=.95$, CFI $=.94$, $\mathrm{NFI}=.94, \mathrm{IFI}=94, \mathrm{SRMR}=.07$ and $\mathrm{RMSEA}=.22$.

\section{Validity}

To test the criterion validity of the scale the BRCS was correlated between the resilience construct and other theo- 
retical constructs associated with resilience. We chose to use, after review of the literature on resilience construct, the scale multidimensional coping styles (Brief COPE) proposed by Carver (1997) that allows to assess 14 different coping strategies: active coping; planning; coping/positive reframing; acceptance; coping with humour; religion; emotional support; instrumental support; self-distraction; denial; behavioural disengagement; substance use or drug behaviour denial and self-blame.

Table 2 shows significant correlations with a confidence level of $p<0.01, * p<.05$ for each Brief factors Carver Cope (1997) with the resiliency factor BRCS (Sinclair \& Wallston, 2004). Positive correlations were obtained in all the scale factors Brief Cope (Carver, 1997) and resilience factor $(p<.05$.) Highlighting the higher correlations for the factors: planning $(r=.62)$, reframing $(r=.60)$ and active coping $(r=.57)$.

Table 2. Correlations of the Brief Resilience Coping Scales (BRCS) with measures of BRIEF Cope (Carver, 1997).

\begin{tabular}{lc}
\hline & Resilience \\
\hline Self-distraction & $.445^{* *}$ \\
Active coping & $.572^{* *}$ \\
Denial & $.164^{* *}$ \\
Abuse of substances & $.066^{*}$ \\
Emotional support & $.325^{* *}$ \\
Behavioural disengagement & $.254^{* *}$ \\
Denial behaviour & $.354^{* *}$ \\
Reframing & $.607^{* *}$ \\
Planning & $.612^{* *}$ \\
Humour & $.344^{* *}$ \\
Acceptance & $.555^{* *}$ \\
Religion & $.287^{* *}$ \\
Instrumental support & $.347^{* *}$ \\
Self-blame & $.250^{* *}$ \\
\hline$* * . p<.01 ; * p<.05$. &
\end{tabular}

\section{Discussion}

The BRCS scale adaptation to a sample of Spanish pensioners has shown, with certain limitations, adequate psychometric properties. Regarding the internal consistency of the instrument, this study has shown a higher reliability than that obtained by the validation made by Tomas et al. (2012), as well as the original instrument by Wallston and Sinclair (2004) Also, homogeneity indices were higher than those of the two works cited. This reinforces the dimensional structure of the BRCS, more if you consider that this onedimensional factor explaining the $70.39 \%$ achieved the total variance explained. Furthermore, the goodness of fit indices was similar to those obtained by Tomas et al. (2012) and the original Sinclair and Wallston (2004).

\section{References}

Bentler, P.M. (1990). Comparative fit indices in structural models. Psychological Bulletin, 107, 238-246.

Bollen, K.A. (1989). A new incremental fit index for general structural equations models. Sociological Methods and Research, 17, 303-316.
For these reasons, this paper provides a validation of the Brief Resilient Coping Scale in Spanish language for overcoming the barrier of assessing the elderly. As with Tomas et al. (2012), the instrument showed optimal values in terms of internal consistency and criterion validity. However, the important aspect of the work is to confirm the results suggested in the initial validation and ultimately use this for other studies.

On the other hand, this work has the following limitations: first, the sample was selected through non-probability sampling, which can introduce distortions in the results when you consider that the final sample may have a high component of self; second, the translation of the original instrument into Spanish was conducted through simultaneous translation of several investigators and subsequent analysis of convergence between them, and through a process of reverse translation of native language experts. However, it should be noted that the language and syntax of the original elements as well as the vocabulary used, are simple and easy to understand, which can greatly reduce the possible bias in the Spanish language adaptation by this procedure; lastly, there is a significantly higher number of men than women, which means the results may vary in populations with a greater parity sample, especially considering that this phase of retirement is experienced differently according to gender variable (Madrid \& Garcés, 2000).

\section{Conclusions}

This work shows the psychometric properties of the scale BCRS, overcoming potential limitations in terms of sample size of Tomas et al. (2012), which can be implemented in populations of other Spanish-speaking countries. First, remember the importance of this type of study for Anglo populations. This validation of the Brief Resilient Coping Scale will examine the role of resilience in the Spanish elderly differentiating between levels or variables that may relate to the concept of resilience. Secondly, this type of study could lay the groundwork for future research, from studies examining the relationship between resilience, quality of life, perceived health and objective health during retirement, using, for example, models of structural equations to crosscultural studies that allow us to compare different populations of the same age group. This will allow the advancement of research on aging and associated psychosocial variables as well as implications for health and age groups. World demographic trends for the coming decades show these areas to be priorities of social and economic policies for societies and developed countries.

Cabib, S., Campus, P., \& Colelli, V. (2012). Learning to cope with stress: psychobiological mechanisms of stress resilience. Reviews in the Neurosciences, 23, 659-672. DOI:10.1515/revneuro-2012-0080

Carver, C.S. (1997). You want to measure doping but your protocol's too long: Consider the BRIEF-COPE. International Journal Behavioral Medicine, 4, 94-100. 
Carver, C. S., Scheier, M. F., y Weintraub, J. K. (1989). Assessing coping strategies: A theoretically based approach. Journal of Personality and Social Psychology, 56 (2), 267-283.

Crespo, M., y Cruzado, J. A. (1997). La evaluación del afrontamiento: adaptación española del cuestionario COPE con una muestra de estudiantes universitarios. Análisis y Modificación de conducta, 23, 797-830.

Comrey, A. L. (1973a). A first course in factor analysis. Nueva York: Academic Press.

Diehl, M., \& Hay, E. L. (2010). Risk and resilience factors in coping with daily stress in adulthood: The role of age, self-concept incoherence, and personal control. Developmental Psychology, 46(5), 1132.

Harkness, J.A., Schoua-Glusberg, A. (1998). Questionnaires in Translation. Zuma-Nachrichten Sperial. January, pp. 87-126.

Harman, H.H. (1976). Modern factor analysis, $3^{\text {rd }}$ Ed., Chicago: University of Chicago Press.

Hu, L. \& Bentler, P.M. (1999). Cut-off criteria for fit indexes in covariance structure analysis: conventional criteria versus new alternatives. Structural Equation Modeling, 6, 1-55.

Jöreskog, K.G. and Sörbom, D. (1979). Advanced in factor analysis and structural equation models. Cambridge: M.A. Abl.

Kaiser, H.F. (1974). An index of factorial simplicity. Psychometrika, 35, 401415.

Madrid, A.J. \& Garces de los Fayos, E.J. (2000). La preparación para la jubilación: revisión de los factores psicológicos y sociales que inciden en un mejor ajuste emocional al final del desempeño laboral. Anales de Psicología, 16, 87-99.

McAslan, A. (2009). The Concept of Resilience. Adelaide: Torrens Resilience Institute.

Rowe, J. W., \& Kahn, R. L. (1987). Human aging: usual and successful. Science, 237(4811), 143-149.

Shaikh, A., Kauppi, C., Bockett, D., Lancaster, R., Thakur, B., Hamilton, O., \& Masso, A. (2010). Coping strategies as a manifestation of resilience in the face of postpartum depression: experiences of women in Northern Ontario. The International Journal of Interdisciplinary Social Sciences, 5(6), 261273
Saris, W. E. and Stronkhorst, H. (1984). Casual modeling in non-experimental research: an introduction to the LISREL approach. Amsterdam: Sociometric Research Foundation.

Sinclair, V., and Wallson, K. (2004). The development and Psychometric evaluation of the Brief Resilient Coping Scale. Assessment 11, 1, 94-101.

Staudinger, U. M., Marsiske, M., \& Baltes, P. B. (1995). Resilience and reserve capacity in later adulthood: Potentials and limits of development across the life span. Developmental Psychopathology, 2, 801-847.

Steiger, J.H. \& Lind, C. (1980). Statistically based tests for the number of common factors. Paper presented at the annual meeting of the Psychometric Society, Iowa City, IA.

Tabachnick, B. G. y Fidell, L.S. (1989). Using multivariate statistics, $2^{\text {nd }}$ Ed., Northridge, California: Harper Collins Publishers.

Tanaka, K., \& Johnson, N. E. (2010). Social integration and healthy aging in Japan: how gender and rurality matter. Journal of Cross-Cultural Gerontolo$g y$, 25(2), 199-216. DOI: 10.1007/s10823-010-9118-6

Tomás, J.M, Meléndez, J.C., Sancho, P., and Mayordomo, T. (2012). Adaptation and initial validation of the BRCS in an elderly Spanish sample. European Journal of Psychological Assessment, 28, 4, 283-289. DOI: 10.1027/1015-5759/a000108

Vinaccia, S., Quiceno, J. M., \& Remor, E. (2012). Resiliencia, percepción de enfermedad, creencias y afrontamiento espiritual-religioso en relación con la calidad de vida relacionada con la salud en enfermos crónicos colombianos. Anales de Psicología, 28, 2, 366-377.

Von Faber, M., Bootsma-van der Wiel, A., van Exel, E., Gussekloo, J., Lagaay, A. M., van Dongen, E., Knook, D. L., van der Geest, S, Rudi, G., \& Westendorp, R. G. (2001). Successful aging in the oldest old: who can be characterized as successfully aged? Archives of Internal Medicine, $161,22,2694-2700$.

Wagnild, G. (2003). Resilience and successful aging. Comparison among low and high income older adults. Journal of Gerontological Nursing, 29, 12, 4249

(Article received: 11-11-2013; revised: 07-04-2014; accepted: 29-04-2014) 